Portland State University

PDXScholar

\title{
Winter Precipitation Intensity and ENSO/PDO Variability in the Willamette Valley of Oregon
}

\author{
Sarah Praskievicz \\ Portland State University \\ Heejun Chang \\ Portland State University
}

Follow this and additional works at: https://pdxscholar.library.pdx.edu/geog_fac

Part of the Environmental Sciences Commons

Let us know how access to this document benefits you.

\section{Citation Details}

Praskievcz, S., and Chang, H. (2009) Winter precipitation intensity and ENSO/PDO variability in the Willamette Valley of Oregon. International Journal of Climatology 29(13): 2033-2039.

This Article is brought to you for free and open access. It has been accepted for inclusion in Geography Faculty Publications and Presentations by an authorized administrator of PDXScholar. Please contact us if we can make this document more accessible: pdxscholar@pdx.edu. 


\title{
Short Communication
}

\section{Winter precipitation intensity and ENSO/PDO variability in the Willamette Valley of Oregon}

\author{
Sarah Praskievicz and Heejun Chang* \\ Department of Geography, Portland State University, USA
}

\begin{abstract}
There is growing concern about the effects of inter-annual climatic variability, such as the El-Niño Southern Oscillation (ENSO) and the Pacific Decadal Oscillation (PDO), on regional hydrology and water resources. We analysed patterns of wintertime precipitation intensity, using both simple intensity and number of heavy precipitation days per year, for eight stations in northwestern Oregon's Willamette Valley for the period 1972-2006, and examined the separate and combined influence of ENSO and PDO on precipitation intensity. The analysis was accomplished using Kendall's tau and analysis of variance (ANOVA) to determine differences in precipitation intensity among combinations of positive and negative ENSO and PDO phases. The results suggest that the relation between ENSO phase and precipitation intensity is negative in November and positive in April, while the relation between PDO and intensity is negative and strongest in January and March. These varying seasonal associations with ENSO/PDO phase may be related to the Willamette Valley's location in the transitional zone between positive and negative El Niño response and to the moderating effects of out-of-phase ENSO/PDO. This seasonal variability of heavy rainfall has implications for the quantity and quality of regional water resources. Copyright (C) 2009 Royal Meteorological Society
\end{abstract}

KEY WORDS precipitation intensity; climate variability; ENSO; PDO; Willamette Valley; Oregon

Received 28 May 2008; Revised 17 November 2008; Accepted 22 November 2008

\section{Introduction}

It is well known that inter-annual climate variability is of great importance in determining regional hydrological response. Variability of winter precipitation in the western US is associated with such large-scale oceanic and atmospheric phenomena as the El-Niño Southern Oscillation (ENSO) and the Pacific Decadal Oscillation (PDO) (Brown and Comrie, 2004). There is evidence of an increase in the strength of ENSO teleconnections in many regions during the past several decades (Diaz et al., 2001). This increase may be due to the interaction of ENSO with decadal systems such as the PDO, producing stronger teleconnection patterns when there is an in-phase relation (McCabe and Dettinger, 1999; Mote et al., 2003; Higgins et al., 2007). Also, there is some debate in the literature over whether the PDO represents a regime shift between steady states with different statistics or a Gaussian process with stationary statistics (Rudnick and Davis, 2003). These interactions complicate attempts to determine relations between large-scale ocean-atmospheric systems and regional precipitation intensity.

An increase in the intensity of precipitation could have several hydrological effects. More precipitation arriving in a shorter time period diminishes the ability of water to

* Correspondence to: Heejun Chang, Department of Geography, Portland State University, USA. E-mail: changh@pdx.edu infiltrate a land surface, leading to increased run-off. This means greater potential for flooding, particularly in urban areas that may already have overworked drainage systems (Kundzewicz, 2003). These flashy run-off events have a negative impact on water quality by flushing pollutants from urban and agricultural land into river systems (Chang and Carlson, 2005). Because more precipitation may run-off than infiltrate the soil, dry periods may occur between precipitation events when less groundwater is available for stream recharge, vegetation growth and human consumptive use.

Teleconnections between large-scale ocean-atmosphere systems, notably ENSO, and regional precipitation patterns have been studied by McCabe and Dettinger (1999), Diaz et al. (2001), and Higgins et al. (2007) in North America. A region where ENSO teleconnections are particularly strong is the North Pacific during winter (Spencer and Slingo, 2003). Accordingly, Mote et al. (2003) found that ENSO and the more recently discovered PDO have a substantial influence on inter-annual climatic variability in the Pacific Northwest (PNW), affecting streamflow, snowpack, flooding, salmon survival, forest growth and wildfire risk. ENSO and PDO tend to reinforce one another when they are in the same phase and moderate their effects when they are out-ofphase (Mote et al., 2003). In the Pacific Northwest, El Niño years and the warm phase of the PDO are generally associated with drier than average winters and $\mathrm{La}$ 
Niña and the cool PDO phase with exceptionally wet winters. Stahl et al. (2006) examined how winter synoptic circulation in British Columbia is affected by largescale ocean-atmosphere fluctuations and found significant teleconnections for ENSO/PDO with both temperature and precipitation, although the precipitation anomalies were more complex in their spatial distribution. There is a latitudinal gradient of ENSO teleconnection patterns along the west coast of North America as storm tracks shift northward or southward depending on the phase of ENSO and PDO. South of approximately $43^{\circ} \mathrm{N}$, the precipitation patterns reverse so that El Niño years are associated with higher than average precipitation (Castello and Shelton, 2004). Lying generally within this transition zone is northwestern Oregon's Willamette Valley, a heavily populated and increasingly urbanized region with substantial water resource challenges such as maintaining the needs for in-stream flow and municipal water supply, flood control in a changing climate and population growth (Baker et al., 2004; Chang et al., 2008).

Although there exist studies investigating the relation between winter precipitation and climate variability at seasonal or monthly scale using average amount, few examined how precipitation intensity varies during different phases of ENSO and PDO using individual station data. Our study contributes to the growing body of literature on the interactions of precipitation variability and large-scale atmospheric circulations by examining the relation between ENSO/PDO phase and precipitation intensity for the years 1972-2006 in the Willamette
Valley of Oregon, USA. Understanding patterns in precipitation intensity is of great importance for this region and elsewhere, where water resources have significant ecological, cultural and economic value.

\section{Data and methods}

We obtained daily precipitation data from the Oregon Climate Service (OCS, 2008) for years between 1972 and 2006. Although a longer dataset would have led to more robust results, these years were selected because of the relative completeness of their data records. Because over $70 \%$ of the Willamette Valley's precipitation occurs in winter, and because the ENSO/PDO signal is strongest in winter, only the wet season months of November through April were analysed. Eight National Weather Service sites were selected on the basis of the completeness of their precipitation records (Figure 1). While denser sampling would have allowed for more detailed spatial analysis, the high number of missing days in the data records precluded the inclusion of many sites. The selected sites ranged in elevation from $6 \mathrm{~m}$ at Portland to $216 \mathrm{~m}$ at Lookout Point Dam. The stations had a combined total of 223 missing records during the study period. These missing values were interpolated from the elevationbased regression equation of the nearest two to three stations. When the nearest two stations had no measurable precipitation on a given day, that day was assumed to be dry at the station with the missing record as well.

Once the missing values were interpolated, we aggregated the data by month at each station. We used two

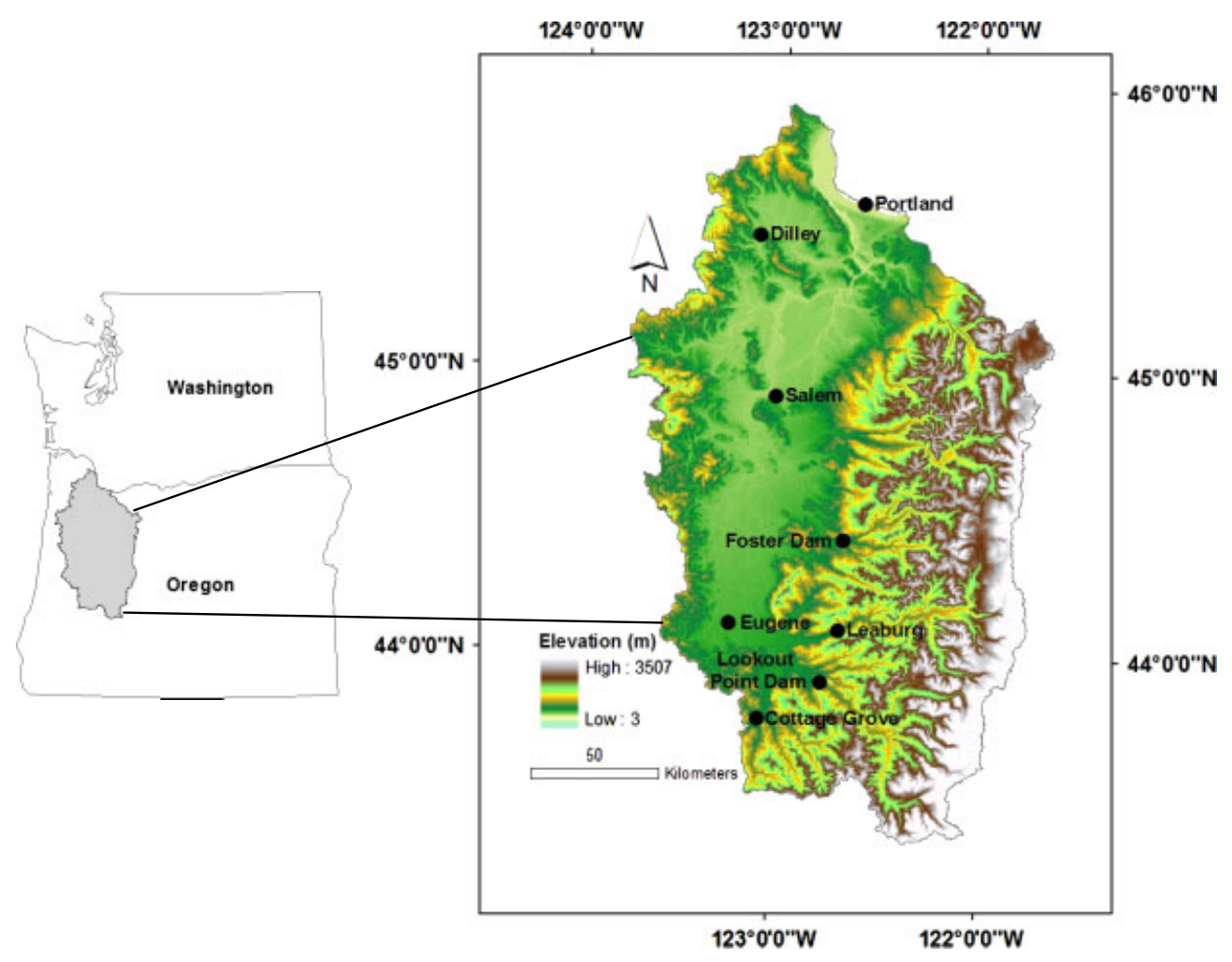

Figure 1. Location of the Willamette Valley within the state of Oregon and of the climate stations. This figure is available in colour online at www.interscience.wiley.com/ijoc 
precipitation intensity indices described by Qian and Lin (2005). The first is a simple intensity index of the amount of precipitation per wet day in each month. It was derived by dividing the total monthly precipitation by the number of wet days in that month. Wet days were defined as those with at least $0.254-\mathrm{mm}$ of daily precipitation. The second index is termed $\mathrm{N}_{95}$. It is the number of days in each year with a precipitation amount that is greater than or equal to the 95th percentile amount for that month during the entire study period. $\mathrm{N}_{95}$ was calculated by ranking the daily precipitation amounts in each month for the entire 35-year period, determining the 95th percentile amount, and counting the number of days in each year that recorded precipitation greater than or equal to that amount.

To assess the influences of ENSO and PDO phase, index values for these phenomena were needed. For ENSO, we obtained values of the Oceanic Niño Index (ONI) for the years 1972-2006 from the National Weather Service's Climate Prediction Center (CPC, 2008). The ONI is based on 3-month running average sea-surface temperature (SST) anomalies, based on the average for the period 1971-2000, in the Nino 3.4 region defined by the coordinates $5^{\circ} \mathrm{N}-5^{\circ} \mathrm{S}$ and $120^{\circ} \mathrm{W}-170^{\circ} \mathrm{W}$ (Trenberth, 1997). For PDO, we used index values for 1972-2006 from the University of Washington and the National Oceanic and Atmospheric Administration's Joint Institute for the Study of the Atmosphere and Ocean (JISAO, 2008). This PDO index is based on SST anomalies in the Pacific Ocean north of $20^{\circ} \mathrm{N}$.

We used two methods to assess the separate influences of ENSO and PDO phase on the two precipitation intensity indices. First, we used Kendall's tau to determine the direction and significance of the relation between ENSO/PDO and intensity for each station in each month. Kendall's tau is appropriate because it is non-parametric and therefore makes no assumptions about the distribution, and it has been used in previous statistical analyses of precipitation intensity (Qian and Lin, 2005; Chang and
Kwon, 2007). Second, to assess differences in intensity for the different phases of ENSO and PDO, we divided the years into warm, neutral and cool and performed an analysis of variance (ANOVA) on the corresponding intensity values, as in Mote et al. (2003). Following the classification of the CPC (2008), El Niño/warm years were defined as those with index values greater than 0.8 , La Niña/cool years were those with index values less than -0.8 and neutral years were those with values between -0.8 and 0.8 . Because of the feedback mechanisms that may operate in the interactions between ENSO and PDO, we also did another set of ANOVA tests of differences in precipitation intensity among four groups consisting of the possible combinations of positive and negative ENSO and PDO to assess the combined influences of these two systems.

\section{Results and discussion}

\subsection{Relation between ENSO and precipitation} intensity

The Kendall's tau test of the relation between ENSO phase and precipitation intensity shows significant results for several months. First, six of the eight stations show a significant negative correlation of ONI value with at least one of the intensity indices in November, indicating that El Niño years are associated with lessintense precipitation at these stations (Figure 2(a)). For the remaining two stations, the direction of the relation was also negative, although not significant. In April, the direction of the relation reverses, with a positive correlation between ONI value and both intensity indices at all stations, at five of which the relation is significant for simple intensity (Figure 2(b)). The ANOVA indicates some significant differences in precipitation intensity exist among El Niño, La Niña, and ENSO-neutral years (Table I). In November, the F statistic is significant for at least one intensity index at five of the eight stations. Also, in April, there were significant differences in simple
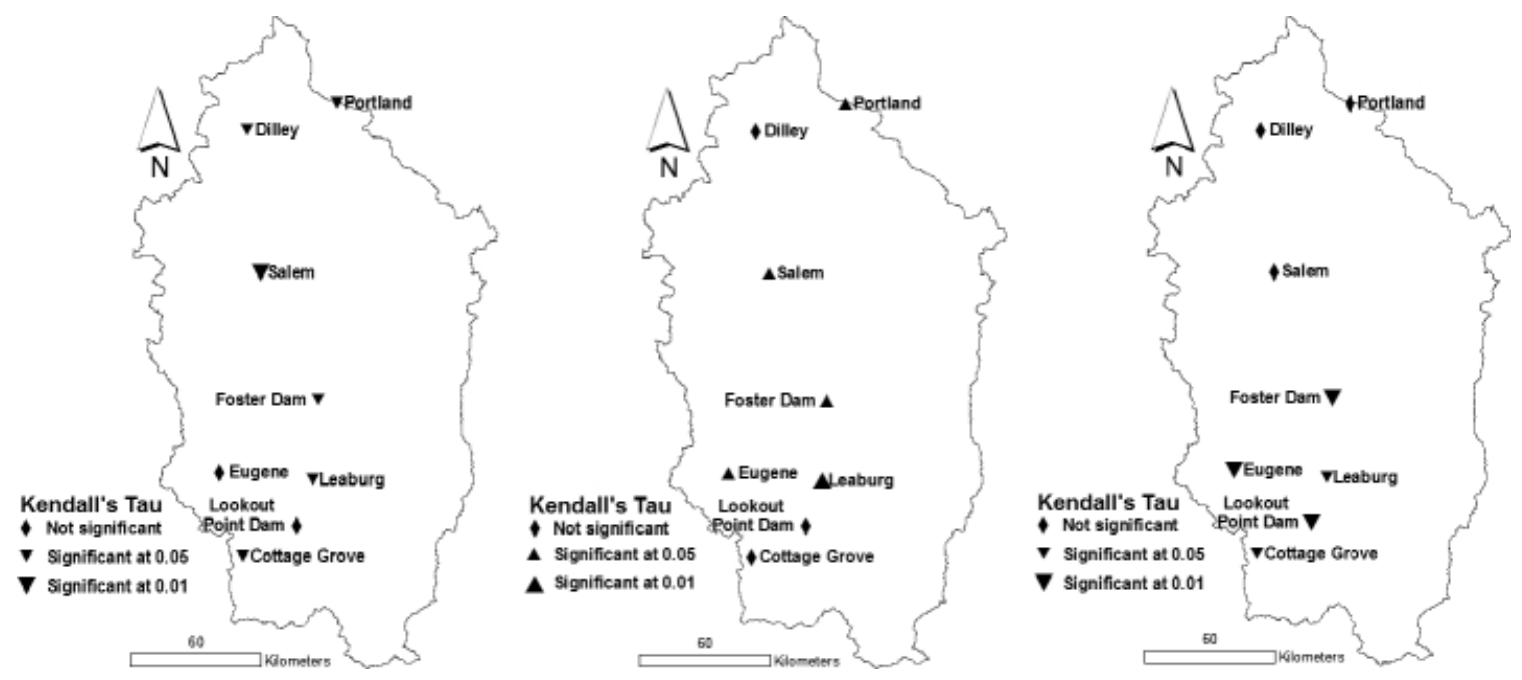

Figure 2. Kendall's tau coefficients for (a) November ONI and precipitation intensity; (b) April ONI and precipitation intensity and (c) January PDO index and precipitation intensity. 
intensity between ENSO phases in Eugene and Salem. During the entire month, only one station (Cottage Grove) exhibited significant difference in both indices.

The direction of the relation between ENSO and November precipitation intensity is what one might expect for the Pacific Northwest, with stronger La Niña being associated with more intense precipitation and stronger El Niño with less intensity at the beginning of the wet season. In April, however, this relation is reversed, with a positive association between ONI and intensity. While a mechanism for such an apparent reversal of effects cannot be determined without further research, it is worth noting that ENSO events tend to decay through the spring, weakening substantially by April (Spencer and Slingo, 2003). This seasonal weakening of teleconnections, combined with the location of the Willamette Valley in the transitional zone between positive and negative El Niño response, may potentially be related to the observed pattern. Also, it is possible that El Niño years may result in a temporal shift of peak precipitation from fall to spring in the Willamette Valley.

\subsection{Relation between PDO and precipitation intensity}

The Kendall's tau test for correlations between PDO phase and precipitation intensity shows significant relations in only 2 months. In January, all stations show a negative relation between PDO index and both intensity indices, and the relation is significant for at least one index at five of the eight stations, indicating that the warm phase of PDO is associated with less-intense precipitation (Figure 2(c)). Also, in April in Salem, there is a significant positive correlation between PDO index and both intensity indices (not shown).

According to the ANOVA, the most significant differences in precipitation intensity among the warm, cool and neutral phases of PDO occurred in March, when six of the eight stations differed significantly in at least one index (Table I). In January, there were significant differences in at least one intensity index for Cottage Grove and Leaburg. Salem also displayed significant differences in simple intensity according to PDO phase in April.

The independent effects of PDO on precipitation intensity in the Willamette Valley are less clear than those of ENSO, which is consistent with the nature of PDO as operating on a longer time scale than ENSO. Most of the years during the study period fall into the warm phase of PDO. For those months with significant and consistent correlations between PDO index and precipitation intensity, the direction of the relation is generally what one might expect, with the cool phase associated with more intense precipitation than the warm phase. According to the ANOVA, at most stations, the significant differences between PDO phases were in January and March, later in the season than the peak ENSO correlations. Another direction for further research might be to explore whether the apparent increasing strength of PDO influence on Willamette Valley precipitation as the winter progresses is related to the decreasing strength of ENSO teleconnections late in the season.

3.3. Relation between the combined effects of ENSO and PDO and precipitation intensity

The combined effects of ENSO and PDO are associated with significant differences in precipitation intensity in several months (Table I). In November, Portland and Salem show significant differences among the different ENSO/PDO phase combinations for both precipitation indices (Figure 3). The intensity is highest for La Niña/warm PDO years, slightly lower for La Niña/cool PDO years and lowest for El Niño/warm PDO years. In January, there are significant differences among phase combinations for at least one of the intensity indices at Cottage Grove and Leaburg. Here, the intensity is highest for El Niño/cool PDO years, followed by La Niña/cool PDO, El Niño/warm PDO and La Niña/warm PDO. In March, phase combination differences exist for at least one intensity index at Cottage Grove and Eugene. In this case, intensity is generally highest for La Niña/cool PDO and El Niño/cool PDO. Finally, in April, significant differences in at least one intensity index among phase combinations were found in four of the eight groups, more than for any other month (Figure 4). Here, intensity was generally highest for El Niño/cool PDO and El Niño/warm PDO and consistently lowest for La Niña/cool PDO. During the entire winter season, three stations exhibited significant differences among phase combinations.

The combined ENSO/PDO ANOVA results reinforce the conclusion that ENSO effects on Willamette Valley precipitation intensity are strongest in November and April. In these months, ENSO phase appears to be more strongly associated with precipitation intensity than PDO phase, although the direction of the relation is again opposite, with El Niño associated with decreased intensity in November and increased intensity in April. In January and March, the highest intensities are associated with the cool phase of the PDO, regardless of ENSO phase. Another noteworthy feature of the results is that in many cases the intensity values are highest in months when ENSO and PDO are out-of-phase, which is contrary to what one might expect. These patterns, along with those of the independent phase analyses, suggest that the relative importance of ENSO and PDO for precipitation intensity in the Willamette Valley may change at the expense of one another as the season progresses, and that their overall interaction with one another may be more moderating than reinforcing in this region. Further research is needed to support these conclusions.

\section{Summary and conclusions}

According to the results of this analysis, the relation between ENSO phase and precipitation intensity is strong and negative in the fall, strong and positive in the spring and weak otherwise, and PDO phase has a stronger association than ENSO in midwinter. For these stations 


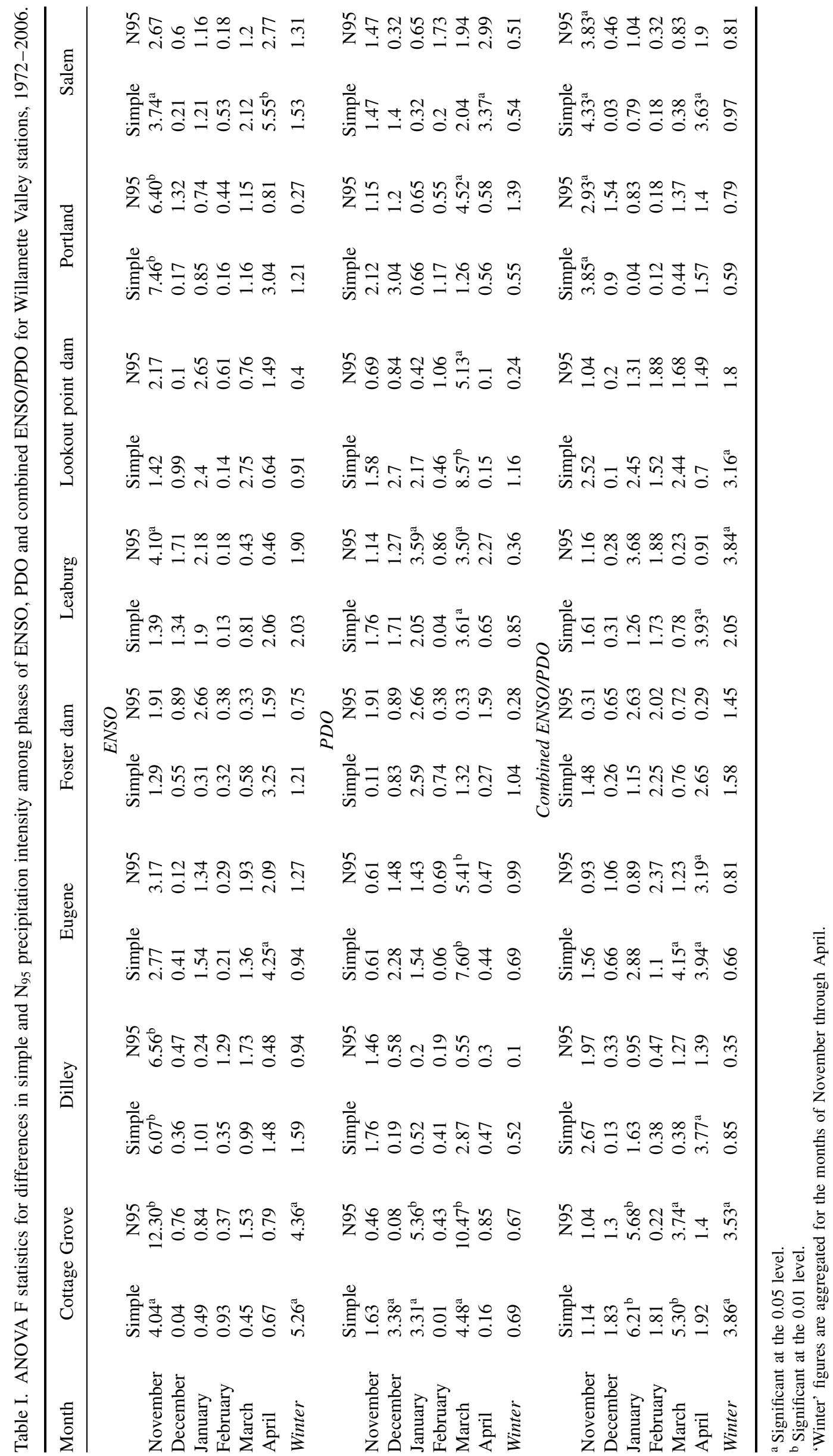



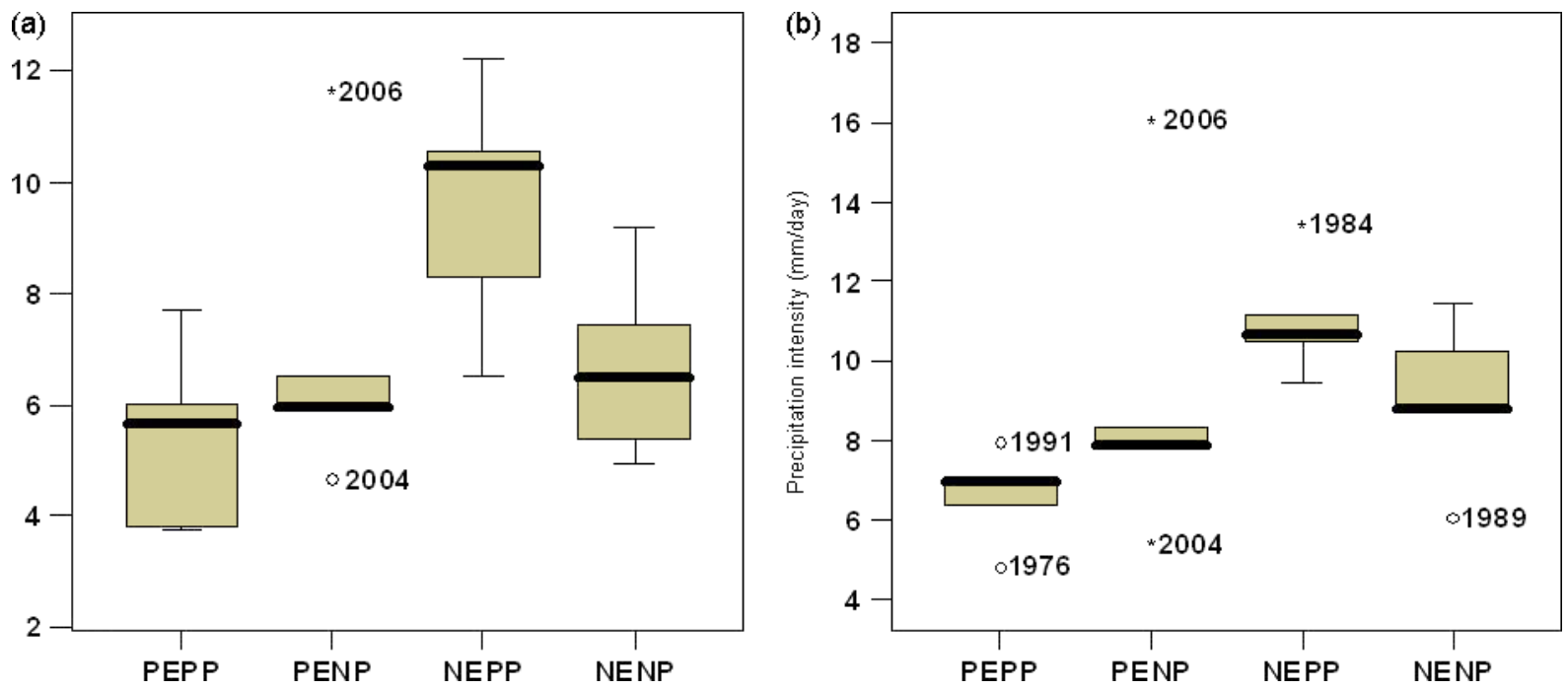

Figure 3. Differences in November simple precipitation intensity among four combinations of positive and negative ENSO/PDO phases for (a) Portland and (b) Salem. Note: PEPP = positive ENSO/positive PDO; PENP = positive ENSO/negative PDO; NEPP = negative $\mathrm{ENSO} /$ positive PDO; NENP = negative ENSO/negative PDO. This figure is available in colour online at www.interscience.wiley.com/ijoc

(a)

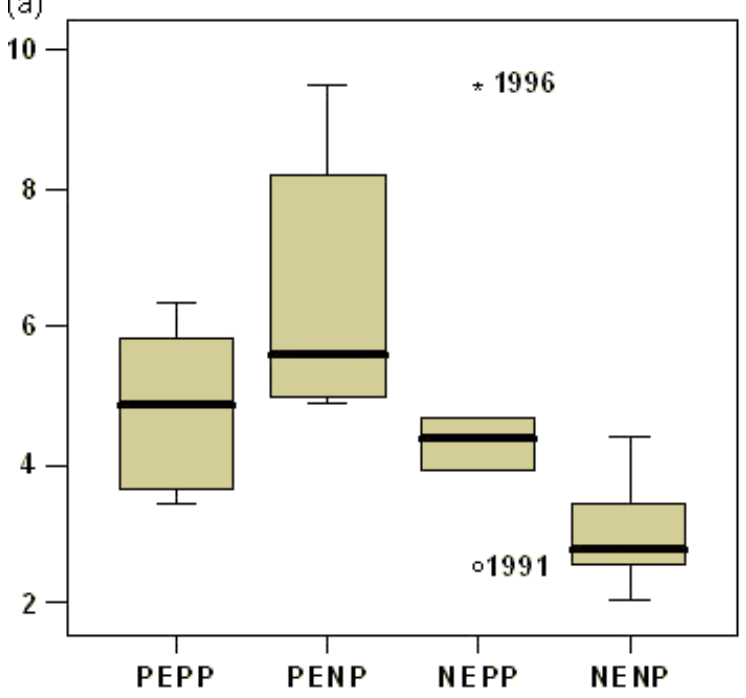

(c)

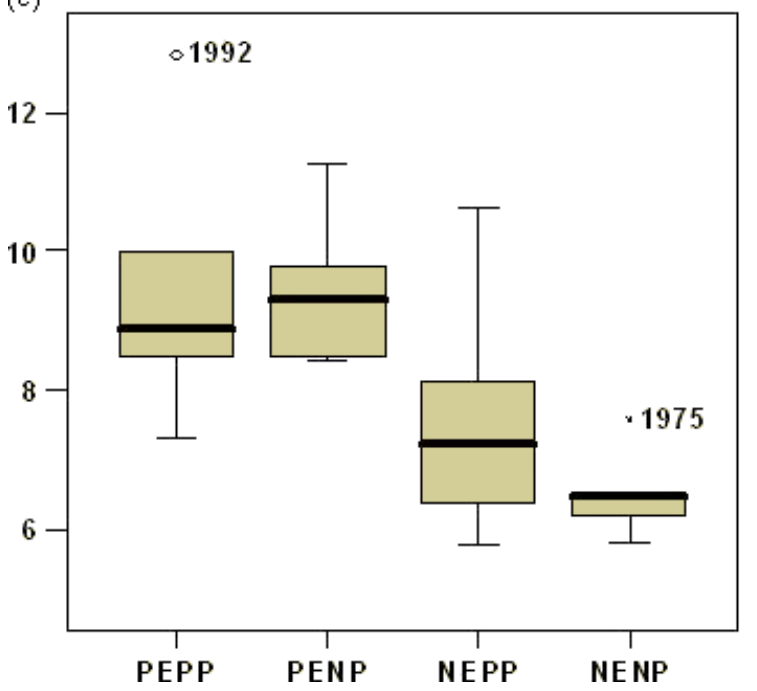

(b)

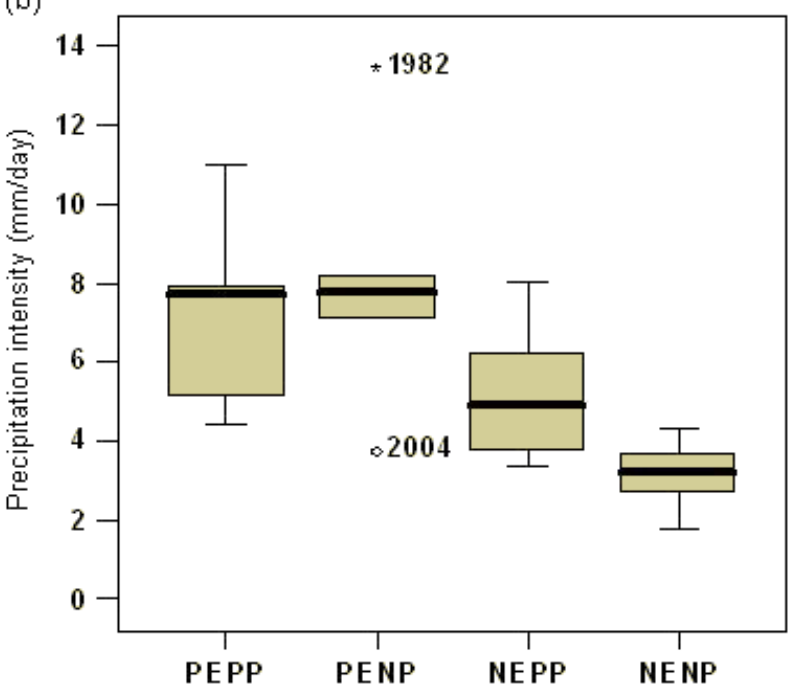

(d)

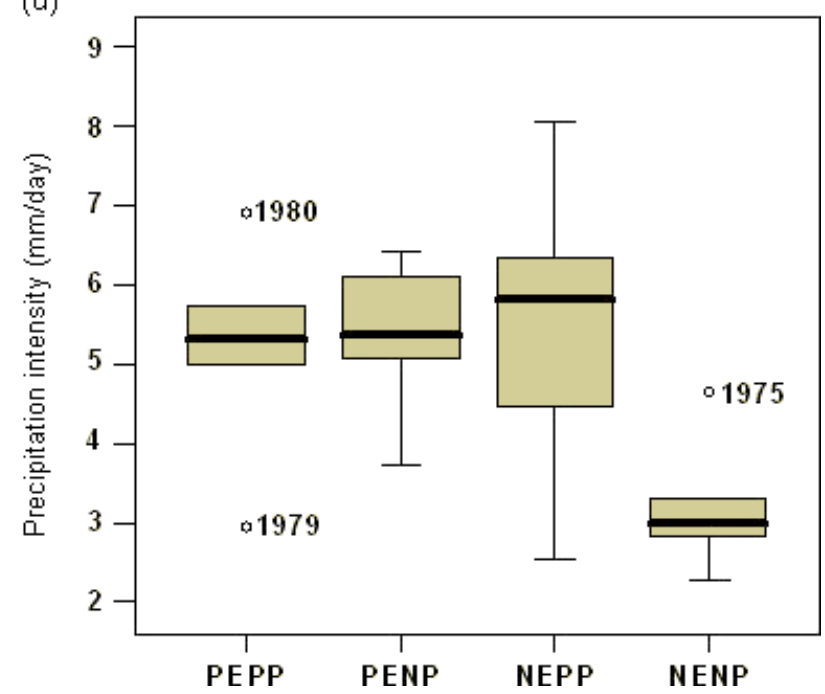

Figure 4. Differences in April simple precipitation intensity among four combinations of positive and negative ENSO/PDO phases for (a) Dilley, (b) Eugene, (c) Leaburg, and (d) Salem. Note: PEPP = positive ENSO/positive PDO; PENP = positive ENSO/negative PDO; NEPP = negative $\mathrm{ENSO} /$ positive PDO; NENP = negative ENSO/negative PDO. This figure is available in colour online at www.interscience.wiley.com/ijoc 
during this time period, the moderating effects of outof-phase ENSO and PDO may be more significant for precipitation intensity than the reinforcing effects of inphase ENSO/PDO.

These conclusions are necessarily tentative due to a number of limitations of this analysis. First, while the study period of 35 years is considered sufficiently long to detect patterns in precipitation intensity (Osborn et al., 2000), a longer time period would allow for more potential patterns to present themselves. Second, this analysis used only eight stations, which may not have been enough to give a full picture of the latitudinal and elevation variability of the Willamette Valley. The incompleteness of the precipitation data record, however, presents challenges to providing fuller temporal and spatial coverage. Third, the analysis could be improved by including more complex indices of precipitation intensity to determine if some intensity measures are more sensitive to ENSO/PDO phase than others.

Despite the preliminary nature of the results, this analysis contributes to existing research on precipitation intensity and ENSO/PDO variability in two major ways. First, it serves as a case study of using individual station data to investigate precipitation intensity and teleconnections. While many previous studies analysed trends in precipitation intensity, and others investigated teleconnections with temperature and total annual precipitation, this study is unique in that it established precipitation intensity teleconnections in the Willamette Valley, a region with complex ENSO/PDO response, using methods that may be replicated elsewhere.

Second, the results suggest that the Willamette Valley's ENSO teleconnections may be strongest at the beginning and end of the rainy season, while PDO dominates in midwinter. This finding implies a need for future investigation of the implications of this seasonal pattern for regional water resources. Higher intensity rainfall at the beginning of the rainy season, when the antecedent moisture condition is dry and pollutants have had a chance to accumulate all summer, may negatively affect water quality through flushing effects. Additionally, intense rainfall at the end of the rainy season may be detrimental to summer flows, as more precipitation runs off rather than infiltrates the soil, diminishing groundwater storage that serves as an important water source during the dry months. These water quantity and quality effects of the seasonal variability of heavy rainfall imply a need for further study of teleconnections and precipitation intensity.

There are many opportunities for further research on the relation between ENSO/PDO and precipitation intensity and its impacts on regional water resources. As governments and other institutions become increasingly concerned with the effects of climate change and variability, there is need to address these issues at the regional level, where adaptation and response takes place. The potential for a long-term increase in precipitation intensity under global warming and for continued inter-annual variability in precipitation would be a significant issue for hydrology and water resources in the mid-latitudes throughout the 21st century. In the Willamette Valley, it remains to be seen what the response will be to the uncertainties of this changing future.

\section{Acknowledgements}

This research was funded by a grant (code \#1-9-3) from the Sustainable Water Resources Research Center of the 21st Century Frontier Research Program in Korea.

\section{References}

Baker JP, Hulse DW, Gregory SV, White D, Van Sickle J, Berger PA, Dole D, Schumaker NH. 2004. Alternative futures for the Willamette River Basin, Oregon. Ecological Applications 14: 313-324.

Brown DB, Comrie AC. 2004. A winter precipitation 'dipole' in the Western United States associated with multidecadal ENSO variability. Geophysical Research Letters 31. DOI: 10.1029/2003GL018726.

Castello AF, Shelton ML. 2004. Winter precipitation on the US Pacific coast and El Niño-Southern Oscillation events. International Journal of Climatology 24: 481-497.

Chang H, Carlson T. 2005. Water quality during winter storm events in Spring creek, Pennsylvania, USA. Hydrobiologia 544: 321-332.

Chang H, Franczyk J, Praskievicz S. 2008. Potential economic impacts of climate change on water resources in the Willamette River basin. In American Geophysical Union Meeting, Fort Lauderdale, May 30. Chang H, Kwon WT. 2007. Spatial variations of summer precipitation trends in South Korea, 1973-2005. Environmental Research Letters 2. DOI: $10.1088 / 1748-9326 / 2 / 4 / 045012$.

Climate Prediction Center (CPC). 2008. ENSO Impacts: Previous Events (1951-Present), Accessed 3/5/08, <http://www.cpc.noaa.gov/ products/analysis_monitoring/ensostuff/ensoyears.shtml $>$.

Diaz HF, Hoerling MP, Eischeid JK. 2001. ENSO variability, teleconnections and climate change. International Journal of Climatology 21: 1845-1862.

Higgins RW, Silva VBS, Shi W, Larson J. 2007. Relationships between climate variability and fluctuations in daily precipitation over the United States. Journal of Climate 20: 3561-3579.

Joint Institute for the Study of the Atmosphere and Ocean (JISAO). 2008. PDO Index, Accessed 3/5/08, <http://jisao.washington.edu/ pdo/PDO.latest $>$.

Kundzewicz ZW. 2003. Extreme precipitation and floods in the changing world. IAHS-AISH Publication 281: 32-39.

McCabe GJ, Dettinger MD. 1999. Decadal variations in the strength of ENSO teleconnections with precipitation in the western United States. International Journal of Climatology 19: 1399-1410.

Mote PW, Parson EA, Hamlet AF, Keeton WS, Lettenmaier D, Mantua N, Miles EL, Peterson DW, Peterson DL, Slaughter R, Snover AK. 2003. Preparing for climatic change: The water, salmon, and forests of the Pacific Northwest. Climatic Change 61: 45-88.

Oregon Climate Service (OCS). 2008. Zone 2 - Climate Data Archives, Accessed 3/5/08. <http://ocs.orst.edu/index.html>.

Osborn TJ, Hulme M, Jones PD, Basnett TA. 2000. Observed trends in the daily intensity of United Kingdom precipitation. International Journal of Climatology 20: 347-364.

Qian W, Lin X. 2005. Regional trends in recent precipitation indices in China. Meteorology and Atmospheric Physics 90: 193-207.

Rudnick DL, Davis RE. 2003. Red noise and regime shifts. Deep-Sea Research I 50: 691-699.

Spencer H, Slingo JM. 2003. The simulation of peak and delayed ENSO teleconnections. Journal of Climate 16: 1757-1774.

Stahl K, Moore RD, McKendry IG. 2006. The role of synoptic-scale circulation in the linkage between large-scale ocean-atmosphere indices and winter surface climate in British Columbia, Canada. International Journal of Climatology 26: 541-560.

Trenberth KE. 1997. The definition of El Niño. Bulletin of the American Meteorological Society 78: 2771-2777. 